\title{
Small Organic Molecule Based on Benzothiadiazole for Electrocatalytic Hydrogen Production
}

\author{
Martin Axelsson, Cleber F. N. Marchiori, Ping Huang, C. Moyses Araujo,* and Haining Tian* \\ Cite This: J. Am. Chem. Soc. 2021, 143, 21229-21233 \\ Read Online
}

ACCESS |

Lلll Metrics \& More

Article Recommendations

Supporting Information

ABSTRACT: A small organic molecule 2,1,3-benzothiadiazole-4, 7-dicarbonitrile (BTDN) is assessed for electrocatalytic hydrogen evolution on glassy carbon electrode and shows a hydrogen production Faradaic efficiency of $82 \%$ in the presence of salicylic acid. The key catalytic intermediates of reduced species $\mathrm{BTDN}^{-\bullet}$ and protonated intermediates are characterized or hypothesized by using various spectroscopic methods and density functional theory (DFT)-based calculations. With the experimental and theoretical results, a catalytic mechanism of BTDN for electrocatalytic $\mathrm{H}_{2}$ evolution is proposed.

U: sing photocatalysis and electrocatalysis to generate clean and renewable fuels from abundant resources such as water and $\mathrm{CO}_{2}$ is one of the most promising directions for replacing fossil fuels. ${ }^{1}$ Development of low-cost, efficient, and environmentally friendly catalysts is therefore vital. To date, the catalysts for these processes have commonly been metal complexes $^{2,3}$ and metallic/organic materials. ${ }^{4,5}$ While often being utilized as ligands in metal complexes or building blocks in organic materials, small organic molecules have not been well studied as catalysts for these types of redox reactions. Recently, small, aromatic, and nitrogen-rich organic compounds have been demonstrated to facilitate both water oxidation $^{6,7}$ and $\mathrm{CO}_{2}$ reduction. $^{8-12}$ When it comes to hydrogen evolution, there are very few reported cases that we know of. ${ }^{13}$ 2,1,3-benzothiadiazole (BT) has been used as a popular electron acceptor blocking unit in many organic polymers for photocatalysis, and we have previously proposed that BT could be an active site for hydrogen production in polymer dots photocatalyst. ${ }^{14-16}$ In this work, we experimentally and theoretically assessed a BT derivative 2,1,3benzothiadiazole-4, 7-dicarbonitrile (BTDN, see Scheme 1) for electrocatalytic hydrogen production and investigated its catalytic mechanism.

Nitrile (CN) groups at the 4 and 7 positions of BTDN have characteristic absorption in the infrared (IR) region, which is vital for monitoring reaction intermediates from the IR spectrum in the following study. Inspired by the study from Cole-Hamilton and coauthors on the photochemical properties of BTDN in micelles, ${ }^{17-19}$ we studied BTDN's electrocatalytic

Scheme 1. Molecular Structure of 2,1,3-Benzothiadiazole-4, 7-dicarbonitrile (BTDN)

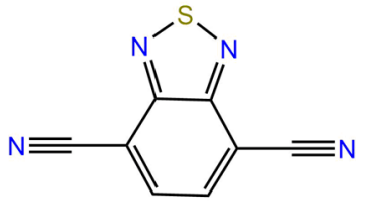

properties in the work. The electrochemical behavior of BTDN is evaluated by cyclic voltammetry $(\mathrm{CV})$, rendering two fully reversible redox waves at -1.06 and $-1.88 \mathrm{~V}$ vs ferrocene/ ferrocenium $\left(\mathrm{Fc} / \mathrm{Fc}^{+}\right)$in acetonitrile, as shown in Figure 1a. The two redox events represent the reduction of BTDN to its anionic radical species $\mathrm{BTDN}^{-\bullet}$ and doubly reduced species $\mathrm{BTDN}^{2-}$, respectively. To check if the reduced species of BTDN can interact with proton, we selected salicylic acid $(\mathrm{SAL})$ with a $\mathrm{p} K_{\mathrm{a}}$ of 16.7 in acetonitrile $(\mathrm{AcN})^{20}$ as the organic acid for this experiment after comparing it with trifluoroacetic acid and acetic acid (Figure S1). SAL offers a broad electrochemical window that allows us to observe the catalytic behavior of BTDN in the presence of protons (Figure S2).

When SAL was introduced to the system as the proton donor, the CV of BTDN (Figure 1a) was significantly perturbed. One can see that the first reduction peak shifts to a less negative potential as compared to that of the pure BTDN as shown in Figure 1a, which is characteristic of an EC (an electrochemical step E, followed by a chemical step C) type process. $^{21}$ At low concentrations, around $50 \mu \mathrm{M}$ BTDN, the shift in the voltage peak with respect to the scan rate and the concentration of the acid correlates well with the prediction of an EC mechanism (Figures S10 and 11). ${ }^{22}$ This can be attributed to a single protonation of the $\mathrm{BTDN}^{-\bullet}$ species forming an organo-hydride species $\mathrm{BTDNH}^{\bullet}$. At higher concentrations, around $250 \mu \mathrm{M}$, increased reductive current is identified when the concentration of acid is increased (Figure 1). It suggests this reaction probably is a homogeneous electron transfer similar to a disproportionation mechanism (DISP), which is further supported by simulations (Figure S12). The electron transfer is coupled to a proton transfer that

Received: October 7, 2021

Published: December 2, 2021 

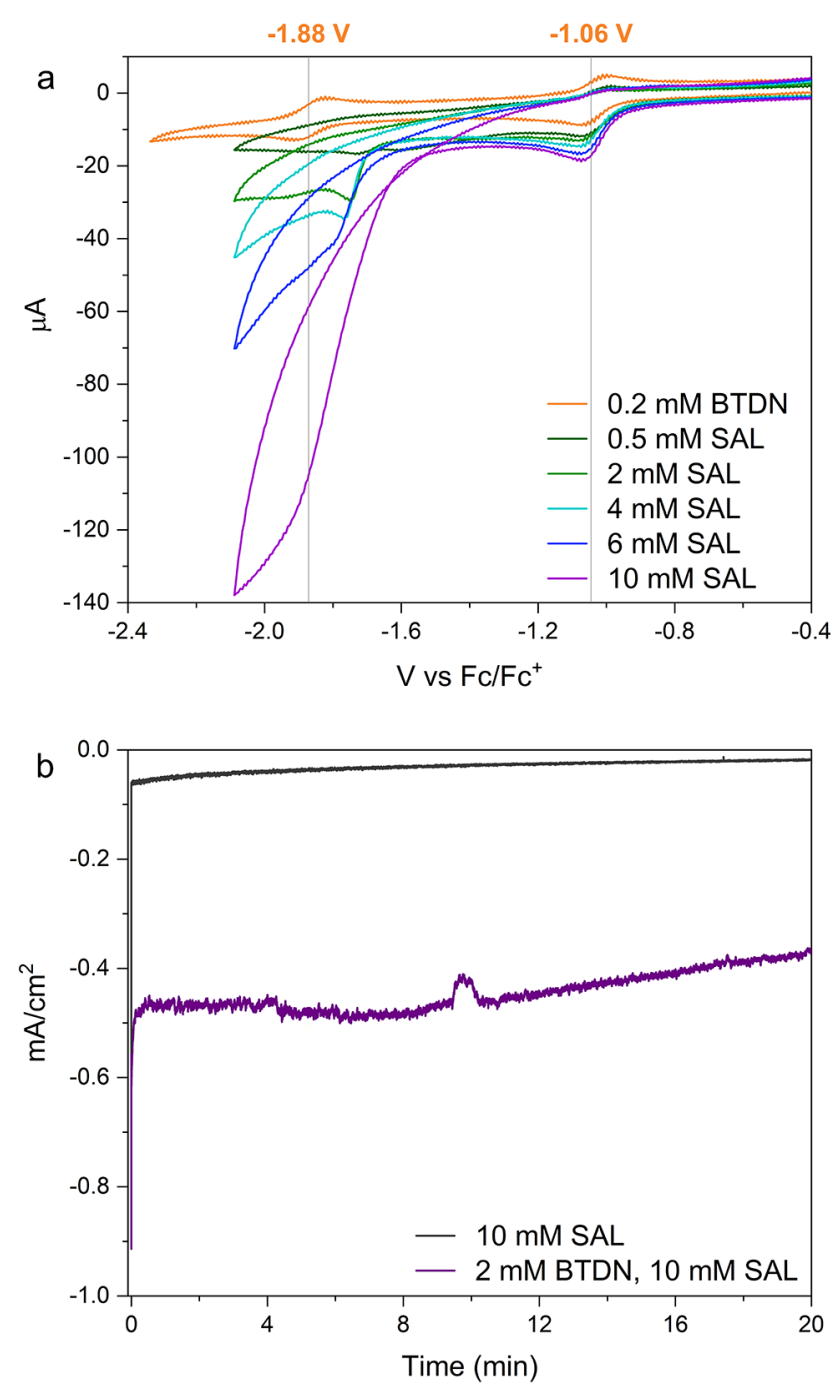

Figure 1. (a) Cyclic voltammetry of BTDN combined with titration of SAL, going from two reversible redox waves for only BTDN (orange) to the fully catalytic behavior with 50 equiv. of SAL (purple). (b) Current from electrocatalytic $\mathrm{H}_{2}$ generation at $-1.65 \mathrm{~V}$ vs $\mathrm{Fc} / \mathrm{Fc}^{+}$from $10 \mathrm{mM} \mathrm{SAL}$ (black) and $2 \mathrm{mM}$ BTDN with $10 \mathrm{mM}$ SAL (purple).

gives a net hydrogen atom transfer (HAT), probably to form a new doubly protonated intermediate, which will be discussed later on with the help from IR data and DFT calculations. Notably, at the higher concentrations, the second redox peak completely disappears and gives way for a catalytic wave with the foot of the wave starting around $-1.6 \mathrm{~V}$ vs $\mathrm{Fc} / \mathrm{Fc}^{+}$.

A titration of BTDN with SAL in CVs measured at every step was subsequently carried out. The corresponding data are shown in Figure 1a. The concentration of SAL was used from 2.5 to 50 equiv. After passing two equivalents of acid, all oxidative current from the second reduction disappears, meaning that all the reduced species have reacted at this point.

To confirm that the catalytic wave appearing is in fact hydrogen evolution, we conducted bulk electrolysis experiments. The electrolysis was performed in the foot of the catalytic wave at $-1.65 \mathrm{~V}$ vs $\mathrm{Fc} / \mathrm{Fc}^{+}$to avoid a large hydrogen evolution from bare SAL and glassy carbon electrode. In the presence of BTDN (Figure 1b), a current density of $0.5 \mathrm{~mA}$ $\mathrm{cm}^{-2}$ was achieved and only $20 \%$ decrease in current in $20 \mathrm{~min}$ was observed. Hydrogen evolution was also detected by gas chromatography (Figure S9) and a Faradaic efficiency was determined to be $82 \%$, the loss can be attributed to the degradation of SAL on the surface of the electrode or decomposition of some BTDN. Without BTDN, only a 0.06 $\mathrm{mA} \mathrm{cm}{ }^{-2}$ current was obtained and decreased rapidly. Only a tiny amount of hydrogen was produced with a very low Faradaic efficiency of $25 \%$. To appraise the TON of the catalyst, we ran a longer experiment in a $3 \mathrm{~mL}$ solution with a 0.2 mM BTDN catalyst (Figure S13), which evolved into 8.1 $\mu \mathrm{mol}$ of $\mathrm{H}_{2}$, giving a TON of 13 . This result suggests that the BTDN indeed works for electrocatalytic hydrogen production. It is worth noting that TON is counted with all BTDN in the reactor, not only the BTDN participating in catalysis on the electrode.

To investigate the catalytic mechanism of BTDN for proton reduction, we attempted to monitor the reaction intermediates by electron paramagnetic resonance (EPR), spectroelectrochemistry (SEC), FTIR spectroscopy and nuclear magnetic resonance (NMR). Because of the reduction occurs before any chemical step in the first reduction peak, the first intermediate is determined to be the $\mathrm{BTDN}^{-\bullet}$ radical anion. The radical is also previously mentioned in literature and is incredibly stable. ${ }^{17}$ The $\mathrm{BTDN}^{-\bullet}$ radical was therefore generated through bulk electrolysis in an inert environment, showing NMR silent in aromatic region (Figure S14). EPR measurement of the BTDN $^{-}$(Figure S15) gave 27 splitting peaks. It means that the radical has hyperfine coupling to two $\mathrm{N}$ atom site. This result is in consistent with previously reported data and indicates that the radical is completely delocalized over the entire molecule, ${ }^{17}$ which is also consistent with our DFT calculations (Figure S20).

To further probe the intermediates during the catalytic cycle, we performed SEC in an inert atmosphere. First, BTDN was studied in the absence of the organic acid. The result is shown in Figure 2a and Figure S16. One can see the characteristic absorption from $\mathrm{BTDN}^{-}$(Figure S15) appears when the applied potential $\left(-1.1 \mathrm{~V}\right.$ vs $\left.\mathrm{Fc} / \mathrm{Fc}^{+}\right)$reaches the first redox potential of BTDN. When a more negative potential $(-1.9 \mathrm{~V}$ vs $\left.\mathrm{Fc} / \mathrm{Fc}^{+}\right)$is applied, the doubly reduced species $\mathrm{BTDN}^{2-}$ appeared with new absorption bands at 520 and $555 \mathrm{~nm}()$. Subsequently, the SEC experiment in the presence of 10 equiv. of SAL was carried out, as shown in Figure 2b. Notably, all features from $\mathrm{BTDN}^{-\bullet}$ and $\mathrm{BTDN}^{2-}$ completely disappear. Instead, there is a new species with an absorption feature at $340 \mathrm{~nm}$ appearing at a potential of $-1.1 \mathrm{~V}$ vs $\mathrm{Fc} / \mathrm{Fc}^{+}$, which is attributed to the protonation of $\mathrm{BTDN}^{-}$. When a catalytic potential of $-1.9 \mathrm{~V}$ vs $\mathrm{Fc} / \mathrm{Fc}^{+}$is applied, the feature completely vanishes, which could be attributed to the reformation of the BTDN after catalysis. The bleach at $320 \mathrm{~nm}$ could be from decomposition of SAL, which absorbs in this region, ${ }^{23}$ and from decomposition of BTDN.

FTIR was used to characterize different intermediates generated from the bulk electrolysis. The corresponding data are shown in Figure 3. To follow the changes of the molecule, the characteristic absorption from $\mathrm{C} \equiv \mathrm{N}$ bond stretching is used as an IR probe. ${ }^{24}$ the stretching mode of BTDN absorbs quite weakly as a singular peak at $2235 \mathrm{~cm}^{-1}$. When BTDN was reduced to $\mathrm{BTDN}^{-}$, the absorption peak shifted to a lower value of $2184 \mathrm{~cm}^{-1}$. Such a shift resulted from the delocalized nature of the radical, making the nitrile bond as a part of the conjugated system in BTDN. This also leads to that intensity of the nitrile stretching absorption becomes much 

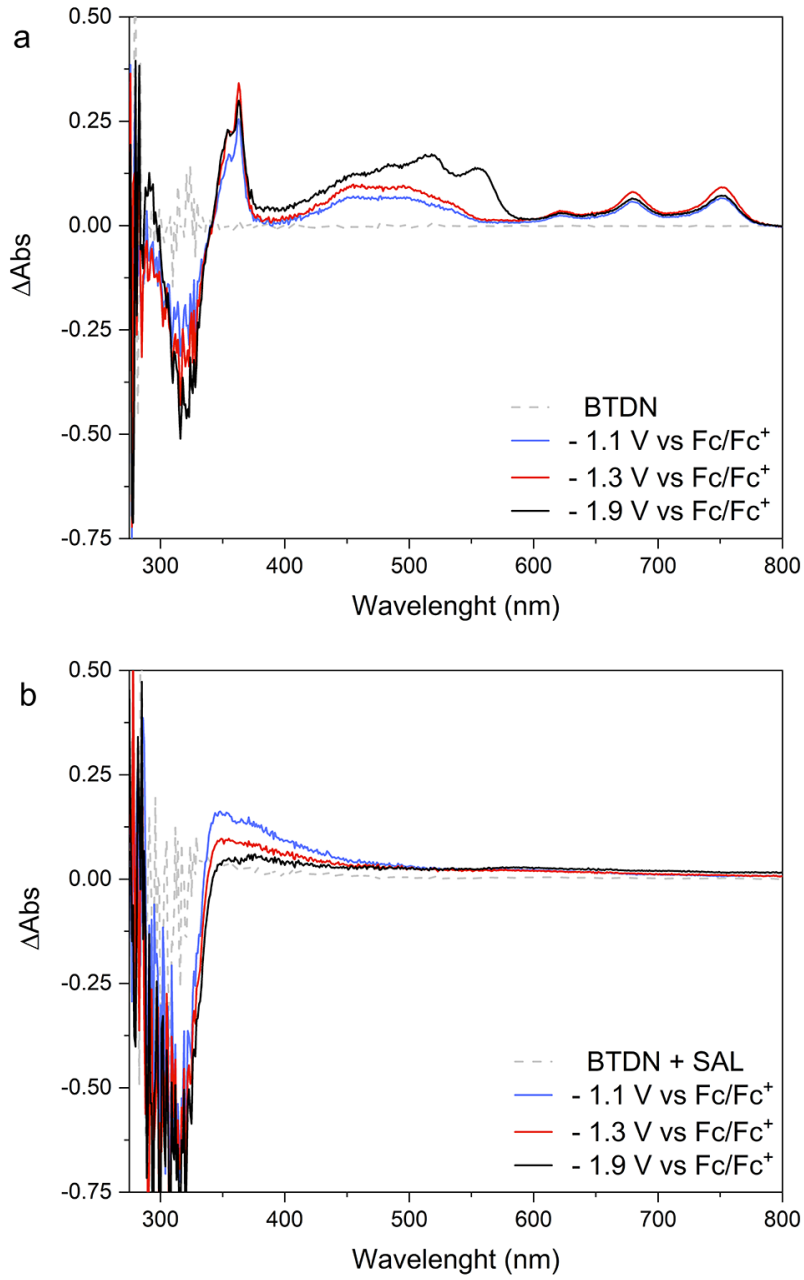

Figure 2. Differential spectra from UV-vis SEC of (a) BTDN and (b) BTDN with SAL at three different potentials of $-1.1 \mathrm{~V}$ (blue), $-1.3 \mathrm{~V}$ (red), and $-1.9 \mathrm{~V}$ vs $\mathrm{Fc} / \mathrm{Fc}^{+}$(black).

stronger, about 10 times as compared to that of the BTDN. When 1 equiv. of SAL was added to $\mathrm{BTDN}^{-\bullet}$ solution, the $2184 \mathrm{~cm}^{-1}$ peak started to disappear; meanwhile, two new peaks at 2235 and $2217 \mathrm{~cm}^{-1}$ appeared.

The new peak at $2217 \mathrm{~cm}^{-1}$ can be attributed to a new protonated species. Notably, half of the reactants return to the unperturbed BTDN species (Figure S17). Combining the electrochemical study with IR and the following DFT calculation, the new protonated species could be doubly protonated BTDN, $\mathrm{BDTNH}_{2}$, ${ }^{25}$ formed from monoprotonated organo-hydride of $\mathrm{BTDN}^{-\bullet}$ followed by the DISP reaction between two $\mathrm{BTDNH}^{\bullet}$ species: $2 \mathrm{BTDN}^{-\bullet}+2 \mathrm{H}^{+} \rightarrow$ $2 \mathrm{BTDNH}^{\bullet} \rightarrow \mathrm{BHDNH}_{2}+\mathrm{BTDN}$. This reaction mechanism is further confirmed by running an operando FTIR-SEC experiment with a $\mathrm{Pt}$ working electrode at a potential of the first reduction (Figure S18). In this experiment all of BTDN can be observed first converting to $\mathrm{BTDN}^{-\bullet}$, and then transforming to the new species with $2217 \mathrm{~cm}^{-1}$ peak, but without the $2235 \mathrm{~cm}^{-1}$ peak returning since the BTDN formed by the DISP reaction is reduced in situ again at the applied potential. The $\mathrm{BTDNH}^{\bullet}$ intermediate that would be required for this step is not clearly visible in the IR spectra, the calculated IR of BTDNH ${ }^{\bullet}$ with two split peaks shows a strong overlap with $\mathrm{BDTNH}_{2}$ (single peak, Figure $3 \mathrm{~b}$ ) which could
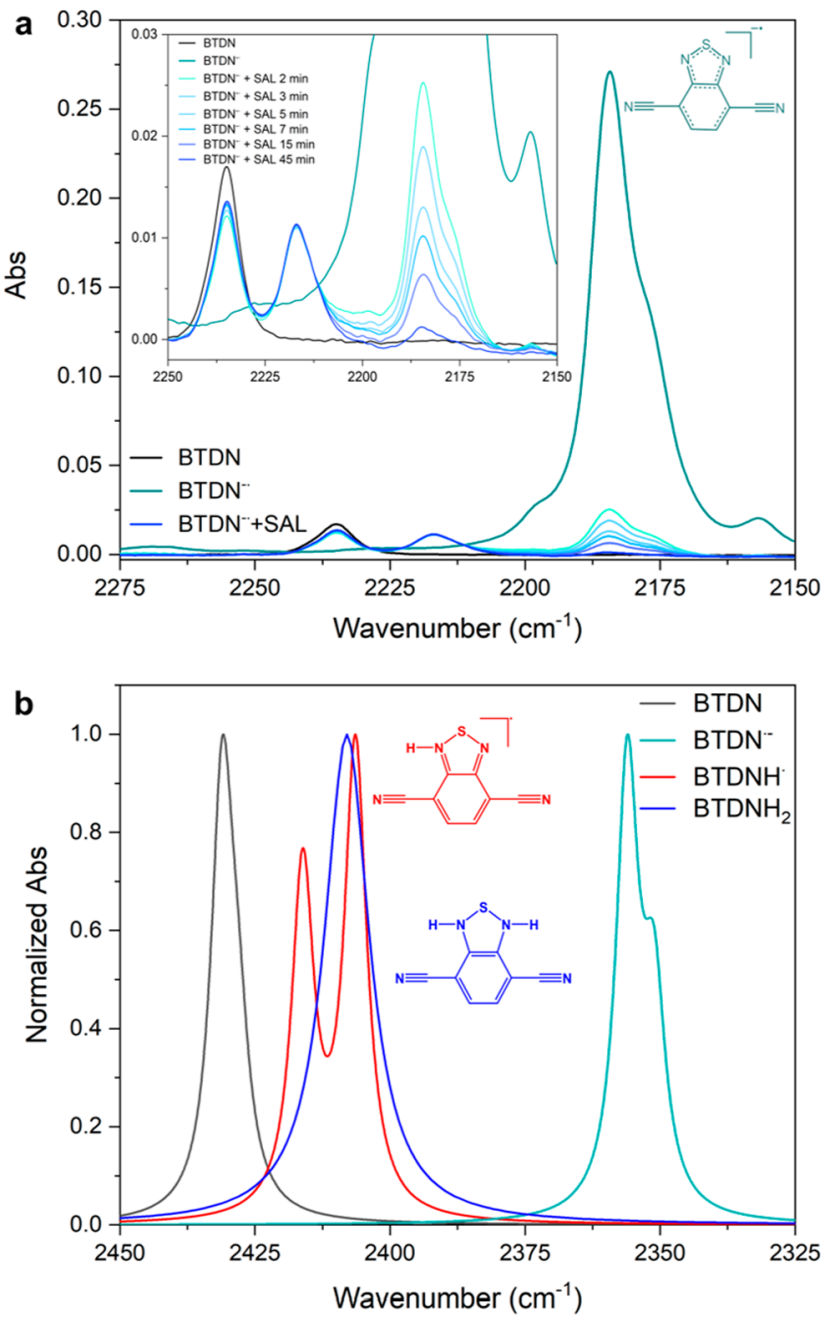

Figure 3. (a) Experimental and (b) calculated FTIR spectra of the catalytic intermediates, (a) BTDN (black), BTDN ${ }^{-\bullet}$ (teal), BTDN ${ }^{\bullet}$ with the addition of 1 equiv. of SAL $\left(\mathrm{BTDN}^{-\bullet}+\mathrm{SAL}\right)$ (blue), and transitions in between the intermediates. Inset showing a zoom in on the decline in $\mathrm{BTDN}^{-\bullet}$ and the growth of $\mathrm{BTDNH}_{2}$ species after the addition of 1 equiv. of SAL. (b) Calculated normalized spectra of BTDN (black), BTDN $^{-}$(teal), BTDNH ${ }^{\bullet}$ (red), and $\mathrm{BTDNH}_{2}$ (blue). Spectra extracted from DFT calculations at the M08-HX/6$311++\mathrm{G}(\mathrm{d}, \mathrm{p})$ theory level.

explain the absence of $\mathrm{BTDNH}^{\bullet}$ species in the spectra. It is also possible that DISP reaction is too fast to be observed under our experimental conditions.

Considering all the possible protonated species from $\mathrm{BTDN}^{-}$, DFT calculations were applied. Comparing the free binding energy, $\Delta G$, of protonation on the reduced BT at the $\mathrm{N}$ - or S-site it is clear that protonation on the $\mathrm{N}$-site is by far the most likely scenario (Figure S21), because the protonation of $S$ has much larger $\Delta G$ than that of the pronation of $\mathrm{N}$. However, the intermediates of the final catalytic step were not captured experimentally due to reaction rates faster than the experimental detection limit. From transition state calculations, by far the most energetically favorable reaction seems to be a hydride donation reaction directly to a proton (SAL) in the solution from the reduced doubly protonated species $\mathrm{BTDNH}_{2}{ }^{-}$(Figure S22).

Combining experimental and theoretical data, an electrocatalytic mechanism for hydrogen evolution from BTDN is 
therefore proposed, as shown in Figure 4. First, BTDN is reduced to $\mathrm{BTDN}^{-\bullet}$ and followed by protonation of $\mathrm{BTDN}^{-\bullet}$

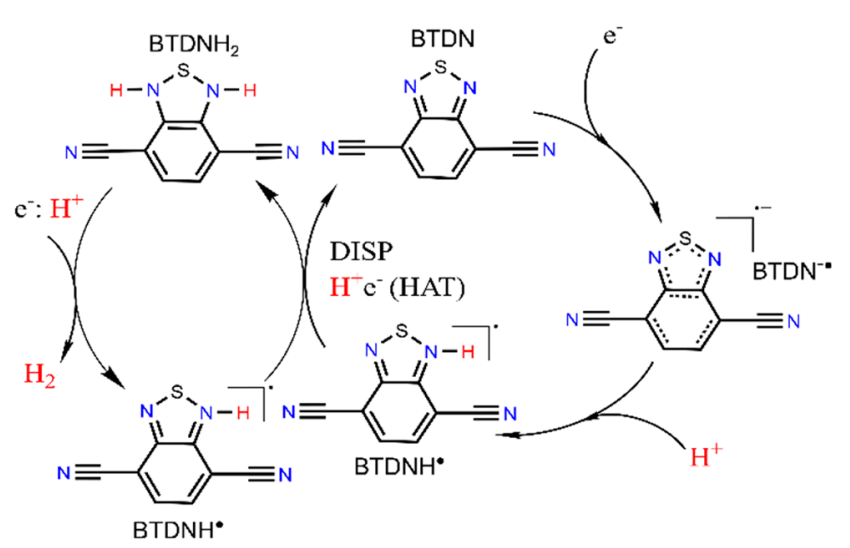

Figure 4. Proposed catalytic mechanism for electrocatalytic hydrogen evolution from BTDN.

radical anion at the $\mathrm{N}$-site via an $\mathrm{EC}$ reaction in the presence of an acid to form an organic hydride radical $\mathrm{BTDNH}^{\bullet}$. Subsequently, a net HAT reaction occurs between two $\mathrm{BTDNH}^{\bullet}$ species to form the $\mathrm{BTDNH}_{2}$ species and BTDN. A more reductive voltage is needed to get into the final catalytic wave, where the $\mathrm{BTDNH}_{2}$ species is reduced again. And looking at the energetics of $\mathrm{H}_{2}$ formation, seemingly a hydride type transfer happens to form $\mathrm{H}_{2}$ and the BTDNH ${ }^{\bullet}$ species which would react further. As no hydrogen was detected from the first reduction peak, it indicates that the second reduction of $\mathrm{BTDNH}_{2}$ is necessary for the catalytic process, further strengthening the proposed mechanism. However, participation of multiple protons in the final catalytic step with $\mathrm{BTDNH}_{2}$ as well as involvement of resonance structures of the intermediates during the catalysis could not be experimentally excluded and therefore needs to be further investigated.

In summary, we have demonstrated a small organic molecule 2,1,3-benzothiadiazole-4, 7-dicarbonitrile (BTDN) that shows electrocatalytic hydrogen evolution on glassy carbon electrode in the presence of salicylic acid in acetonitrile. Reaction intermediates have been captured or proposed according to EPR, UV-vis SEC, IR, NMR, and DFT calculation. Eventually, an electrocatalytic mechanism of BTDN for electrocatalytic hydrogen production is proposed. This work paves the road for development and study of small organic catalysts for hydrogen production. The result also provides information to understand the role of benzothiadiazole unit in some functional materials such as covalent organic framework and mesoporous organic semiconducting polymers used for electro- or photocatalytic hydrogen production. More research work on understanding the final catalytic step of BTDN for hydrogen production, investigating other potential reaction mechanism and studying the effect of BTDN-type molecular structures on catalytic hydrogen evolution, $\mathrm{CO}_{2}$ reduction, and organic photoredox catalysis is ongoing.

\section{- ASSOCIATED CONTENT}

SI Supporting Information

The Supporting Information is available free of charge at https://pubs.acs.org/doi/10.1021/jacs.1c10600.
Experimental details, control experiments, calculation of TON, EPR spectrum, and determination of rate constant and the computational method/results (PDF)

\section{AUTHOR INFORMATION}

\section{Corresponding Authors}

C. Moyses Araujo - Department of Engineering and Physics, Karlstad University, Karlstad 65188, Sweden; Department of Physics and Astronomy, Angström Laboratory, Uppsala University, Uppsala 751 20, Sweden; (1) orcid.org/00000001-5192-0016; Email: moyses.araujo@kau.se

Haining Tian - Department of Chemistry-Ångström Laboratory, Uppsala University, Uppsala SE 751 20, Sweden; orcid.org/0000-0001-6897-2808; Email: haining.tian@kemi.uu.se

\section{Authors}

Martin Axelsson - Department of Chemistry-Ångström Laboratory, Uppsala University, Uppsala SE 751 20, Sweden

Cleber F. N. Marchiori - Department of Engineering and Physics, Karlstad University, Karlstad 65188, Sweden; 다이.org/0000-0003-0377-3669

Ping Huang - Department of Chemistry-Ångström Laboratory, Uppsala University, Uppsala SE 751 20, Sweden

Complete contact information is available at:

https://pubs.acs.org/10.1021/jacs.1c10600

\section{Funding}

Swedish Research Council (grant 2017-03757, 2020-05223).

\section{Notes}

The authors declare no competing financial interest.

\section{ACKNOWLEDGMENTS}

We gratefully thank the financial support from Swedish Research Council (grant 2017-03757, 2020-05223). C.F.N.M. and C.M.A. thank the Swedish National Infrastructure for Computing (SNIC) at the PDC Center for HighPerformance Computing and National Supercomputer Center at Linköping University (NSC) and acknowledge additional financial support by the Swedish Energy Agency (grant 454201) and STandUP for Energy collaboration. We greatly thank Prof. Sascha Ott, Dr. Reiner Lomoth, Dr. Brian McCarthy, and Dr. Mun Hon Cheah for insightful discussions.

\section{REFERENCES}

(1) Hammarström, L.; Hammes-Schiffer, S. Artificial Photosynthesis and Solar Fuels. Acc. Chem. Res. 2009, 42, 1859-1860.

(2) Razavet, M.; Artero, V.; Fontecave, M. Proton Electroreduction Catalyzed by Cobaloximes: Functional Models for Hydrogenases. Inorg. Chem. 2005, 44, 4786-4795.

(3) Berardi, S.; Drouet, S.; Francas, L.; Gimbert-Surinach, C.; Guttentag, M.; Richmond, C.; Stoll, T.; Llobet, A. Molecular Artificial Photosynthesis. Chem. Soc. Rev. 2014, 43, 7501-7519.

(4) Greeley, J.; Jaramillo, T. F.; Bonde, J.; Chorkendorff, I.; Nørskov, J. K. Computational high-throughput screening of electrocatalytic materials for hydrogen evolution. Nat. Mater. 2006, 5, 909-913.

(5) Wang, Y.; Vogel, A.; Sachs, M.; Sprick, R. S.; Wilbraham, L.; Moniz, S. J. A.; Godin, R.; Zwijnenburg, M. A.; Durrant, J. R.; Cooper, A. I.; Tang, J. Current understanding and challenges of solar-driven hydrogen generation using polymeric photocatalysts. Nat. Energy. 2019, 4, 746-760.

(6) Mirzakulova, E.; Khatmullin, R.; Walpita, J.; Corrigan, T.; Vargas-Barbosa, N. M.; Vyas, S.; Oottikkal, S.; Manzer, S. F.; Hadad, 
C. M.; Glusac, K. D. Electrode-assisted catalytic water oxidation by a flavin derivative. Nat. Chem. 2012, 4, 794-801.

(7) Li, H.; Xie, F.; Zhang, M.-T. Metal-Free Electrocatalyst for Water Oxidation Initiated by Hydrogen Atom Transfer. ACS Catal. 2021, 11, 68-73.

(8) Ilic, S.; Pandey Kadel, U.; Basdogan, Y.; Keith, J. A.; Glusac, K. D. Thermodynamic Hydricities of Biomimetic Organic Hydride Donors. J. Am. Chem. Soc. 2018, 140, 4569-4579.

(9) Lim, C.-H.; Ilic, S.; Alherz, A.; Worrell, B. T.; Bacon, S. S.; Hynes, J. T.; Glusac, K. D.; Musgrave, C. B. Benzimidazoles as MetalFree and Recyclable Hydrides for CO2 Reduction to Formate. J. Am. Chem. Soc. 2019, 141, 272-280.

(10) Boston, D. J.; Xu, C.; Armstrong, D. W.; MacDonnell, F. M. Photochemical Reduction of Carbon Dioxide to Methanol and Formate in a Homogeneous System with Pyridinium Catalysts. J. Am. Chem. Soc. 2013, 135, 16252-16255.

(11) Lim, C.-H.; Holder, A. M.; Hynes, J. T.; Musgrave, C. B. Reduction of $\mathrm{CO}_{2}$ to Methanol Catalyzed by a Biomimetic OrganoHydride Produced from Pyridine. J. Am. Chem. Soc. 2014, 136 (45), 16081-16095.

(12) Vasilyev, D. V.; Dyson, P. J. The Role of Organic Promoters in the Electroreduction of Carbon Dioxide. ACS Catal. 2021, 11 (3), 1392-1405.

(13) Baumgartel, H.; Retzlav, K.-J.; Bard, A. J.; Dekker, M. Heteroaromatic Compounds. In Encyclopedia of Electrochemistry of the Elements XV; Marcel Dekker: New York, 1984; p 194, .

(14) Pati, P. B.; Damas, G.; Tian, L.; Fernandes, D. L.; Zhang, L.; Pehlivan, I. B.; Edvinsson, T.; Araujo, C. M.; Tian, H. An experimental and theoretical study of an efficient polymer nanophotocatalyst for hydrogen evolution. Energy Environ. Sci. 2017, 10, 1372-1376.

(15) Yang, C.; Ma, B. C.; Zhang, L.; Lin, S.; Ghasimi, S.; Landfester, K.; Zhang, K. A. I.; Wang, X. Molecular Engineering of Conjugated Polybenzothiadiazoles for Enhanced Hydrogen Production by Photosynthesis. Angew. Chem. 2016, 128, 9348-9352.

(16) Wang, L.; Fernández-Terán, R.; Zhang, L.; Fernandes, D. L. A.; Tian, L.; Chen, H.; Tian, H. Organic Polymer Dots as Photocatalysts for Visible Light-Driven Hydrogen Generation Angew. Angew. Chem., Int. Ed. 2016, 55, 12306-12310.

(17) Camilleri, P.; Dearing, A.; Cole-Hamilton, D. J.; O’Neill, P. One-Electron Reduction of 2,1,3-Benzothiadiazole-4,7-dicarbonitrile in Aqueous Solutions. J. Chem. Soc., Perkin Trans. 2 1986, 2, 569-572.

(18) Dainty, C.; Bruce, D. W.; Cole-Hamilton; Camilleri, P. The Photochemical Reduction of 2,1,3-Benzothiadiazole-4,7-dicarbonitrile by Ethylenediaminetetra-acetic acid in the Presence of Micelles. J. Chem. Soc., Chem. Commun. 1984, 860, 1324-1325.

(19) Robinson, J. N.; Cole-Hamilton, D. J.; Camilleri, P. The Photochemical Reduction of 2,1,3-Benzothiadiazole-4,7- dicarbonitrile in the Presence of Cationic Micelles, and Onward ElectronTransfer Reactions. J. Chem. Soc., Faraday Trans. 1 1989, 85, 33853394.

(20) Kütt, A.; Leito, I.; Kaljurand, I.; Sooväli, L.; Vlasov, V. M.; Yagupolskii, L. M.; Koppel, 1. A. A Comprehensive Self-Consistent Spectrophotometric Acidity Scale of Neutral Brønsted acids in Acetonitrile. J. Org. Chem. 2006, 71, 2829-2838.

(21) Savéant, J.-M. Elements of Molecular and Biomolecular Electrochemistry; John Wiley \& Sons, 2006.

(22) Nicholson, R. S.; Shain, I. Theory of Stationary Electrode Polarography: Single Scan and Cyclic Methods Applied to Reversible, Irreversible, and Kinetic Systems. Anal. Chem. 1964, 36, 706-723.

(23) Salinas, F.; Berzas Nevada, J. J.; Espinosa Mansilla, A. A new spectrophotometric method for quantitative multicomponent analysis resolution of mixtures of salicylic and salicyluric acids. Talanta 1990, 37, 347-351.

(24) Griffith, R. E.; Kitson, N. E. Infrared Absorption Band due to Nitrile Stretching Vibration. Anal. Chem. 1952, 24, 334-337.

(25) Bryce, M. R. Use of Piperidine-1-sulphenyl Chloride as a Sulphur-transfer Reagent in Reactions with Diamines: The Prepara- tion of Sulphur-Nitrogen Heterocycle. J. Chem. Soc., Perkin Trans. 1 1984, 11, 2591-3.

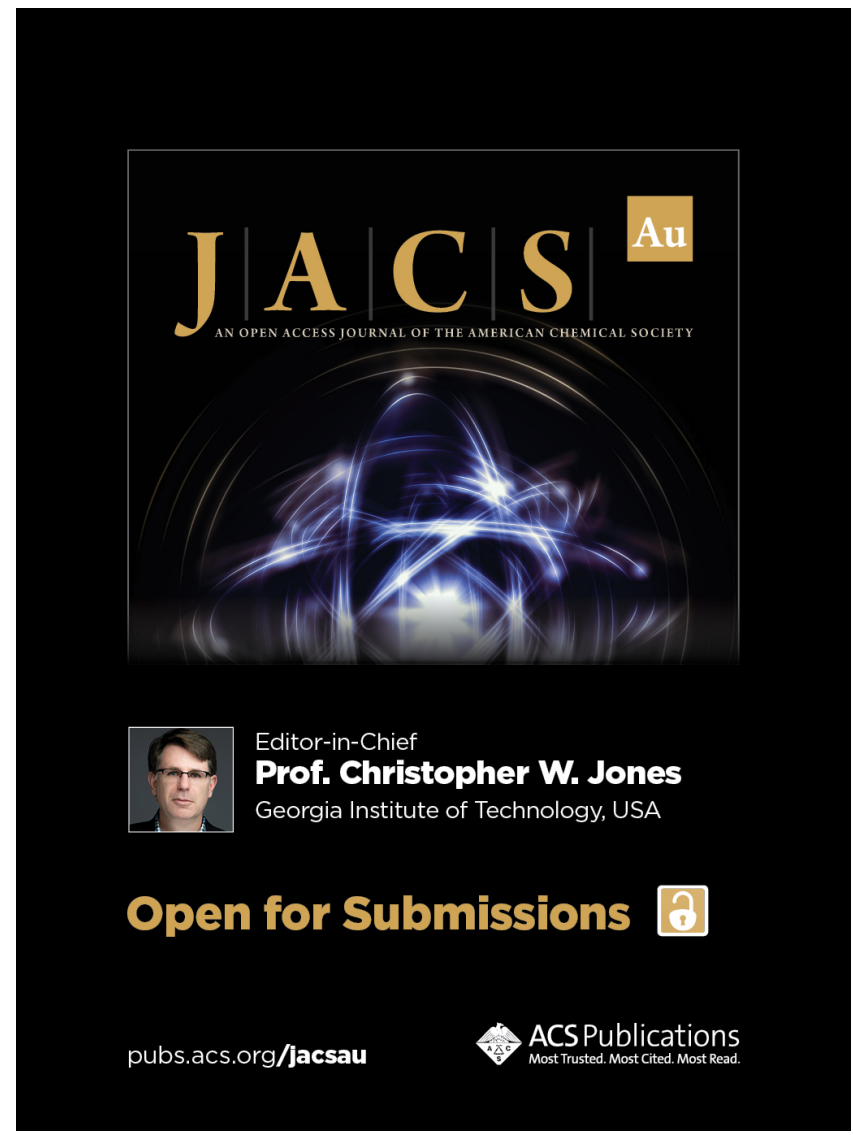

https://doi.org/10.1021/jacs.1c10600 J. Am. Chem. Soc. 2021, 143, 21229-21233 